\title{
Milk as an effective post-exercise rehydration drink
}

\author{
Susan M. Shirreffs*, Phillip Watson and Ronald J. Maughan \\ School of Sport and Exercise Sciences, Loughborough University, Loughborough LE11 3TU, UK
}

(Received 14 July 2006 - Revised 19 January 2007 - Accepted 24 January 2007)

\begin{abstract}
The effectiveness of low-fat milk, alone and with an additional $20 \mathrm{mmol} / \mathrm{l} \mathrm{NaCl}$, at restoring fluid balance after exercise-induced hypohydration was compared to a sports drink and water. After losing 1.8 (SD 0.1) \% of their body mass during intermittent exercise in a warm environment, eleven subjects consumed a drink volume equivalent to $150 \%$ of their sweat loss. Urine samples were collected before and for $5 \mathrm{~h}$ after exercise to assess fluid balance. Urine excretion over the recovery period did not change during the milk trials whereas there was a marked increase in output between 1 and $2 \mathrm{~h}$ after drinking water and the sports drink. Cumulative urine output was less after the milk drinks were consumed (611 (SD 207) and 550 (SD 141) $\mathrm{ml}$ for milk and milk with added sodium, respectively, compared to 1184 (SD 321 ) and 1205 (SD 142) ml for the water and sports drink; $P<0 \cdot 001$ ). Subjects remained in net positive fluid balance or euhydrated throughout the recovery period after drinking the milk drinks but returned to net negative fluid balance $1 \mathrm{~h}$ after drinking the other drinks. The results of the present study suggest that milk can be an effective post-exercise rehydration drink and can be considered for use after exercise by everyone except those individuals who have lactose intolerance.
\end{abstract}

Rehydration: Milk: Water balance: Exercise

Sweat loss generally exceeds fluid intake during exercise so a hypohydrated state at the end of exercise is normal (Broad et al. 1996; Burke \& Hawley, 1997; Maughan et al. 2004b, 2005; Shirreffs et al. 2005). When undertaking regular exercise, any fluid deficit that is incurred during one exercise session can potentially compromise the next exercise session if adequate fluid replacement does not occur. Sweat-induced dehydration can have detrimental effects on physiological function and subsequent exercise performance (Cheuvront et al. 2003; Coyle, 2004) and post-exercise restoration of fluid balance can help minimise this. While it is relatively easy to ensure sweat losses are replaced when exercise is performed infrequently (e.g. once per day or less), when training twice in $1 \mathrm{~d}$, effective restoration of fluid balance may need special attention.

Given the tendency for individuals to fail to match sweat losses during exercise and the relative importance of ensuring the restoration of whole-body fluid balance before the start of a subsequent bout of exercise, post-exercise rehydration has been extensively investigated over the past 15 years (Shirreffs et al. 2004). It is clear that the electrolyte content of the drink consumed plays a key factor in the rehydration process, with the fraction of fluid retained directly related to the amount of ingested sodium (Maughan \& Leiper, 1995; Shirreffs \& Maughan, 1998). There is also some evidence that the addition of potassium in the ingested solution can aid the restoration of fluid balance following exercise-induced dehydration (Nielsen et al. 1986; Yawata, 1990; Maughan et al. 1994). Obligatory urine production, which is necessary to ensure the elimination of non-volatile metabolic waste products, continues even when an individual is in a state of hypohydration. Additionally, the ingestion of large volumes of fluid, in particular solutions with little or no solute content, results in the stimulation of diuresis due to a fall in serum osmolality and a transient increase in plasma volume (Nose et al. 1988). Therefore it is clear that the volume of fluid ingested after exercise must be greater than the volume of sweat lost, with evidence suggesting that a volume equal to around $150 \%$ of the body mass lost should be consumed to ensure adequate restoration of fluid losses (Shirreffs et al. 1996).

In many situations, there may be opportunities to consume food between exercise bouts, and in most situations this can be encouraged unless it is likely to result in gastrointestinal disturbances. Maughan et al. (1996) investigated the role of solid food intake in promoting rehydration from a $2.1 \%$ body mass sweat loss with consumption of either a solid meal plus flavoured water or a commercially available sports drink. The volume of fluid in the meal plus water was the same as the volume of sports drink consumed but the urine volume produced following food and water ingestion was almost $300 \mathrm{ml}$ less than that when the sports drink was consumed. Although the quantity of water consumed with both rehydration methods was the same, the meal had a greater electrolyte content $\left(63 \mathrm{mmol} \mathrm{Na}{ }^{+}\right.$and $21 \mathrm{mmol} \mathrm{K}^{+} v$. $43 \mathrm{mmol} \mathrm{Na}^{+}$and $7 \mathrm{mmol} \mathrm{K}^{+}$) and it seems most likely that the greater efficacy of the meal plus water treatment in restoring whole-body water balance was a consequence of the greater total cation content causing a smaller volume of

Abbreviations: trial CE, carbohydrate-electrolyte sports drink; trial $\mathrm{M}$, milk; trial $\mathrm{M}+\mathrm{Na}$, milk with added $\mathrm{NaCl}$; trial $\mathrm{W}$, water.

* Corresponding author: Dr Susan M. Shirreffs, fax +44 (0)1509 226301, email s.shirreffs@lboro.ac.uk 
urine to be produced. Subsequent studies have also highlighted a role for food products in post-exercise fluid balance restoration (Ray et al. 1998).

Much of the work in this area has focused on the use of experimental solutions prepared in a laboratory, rather than adopting drinks that can be commonly found in the home. The studies described earlier investigating food consumption are exceptions to this and there are a limited number of other studies that also fall into this category (GonzalezAlonso et al. 1992; Saat et al. 2002). Milk is a potential candidate for an effective post-exercise solution, given its naturally high electrolyte content and the presence of carbohydrate in a concentration similar to many commercially available sports drinks. Milk-based drinks have previously been investigated with regard to any potential effect their macronutrients (carbohydrate and protein) may have in an exercise scenario (Karp et al. 2006). However, a potential role in assisting post-exercise rehydration has not yet been established.

Therefore, the aim of the present study was to investigate the effectiveness of low-fat milk at restoring whole-body net fluid balance following mild exercise-induced dehydration. The response to milk ingestion was compared to water, a commercially available sports drink and milk with additional $\mathrm{NaCl}$. Milk with additional $\mathrm{NaCl}$ was investigated because, as described earlier, it has previously been shown that the effectiveness of a drink at achieving fluid retention after exercise-induced dehydration is in direct relationship to the amount of sodium in the drink, at least up to a concentration of $100 \mathrm{mmol} / \mathrm{l}$. Inclusion of the milk with added $\mathrm{NaCl}$ allowed us to investigate if the same type of linear relationship is apparent when the drink contains more nutrients and food compounds. We hypothesised that the two milk drinks would be more effective rehydration solutions than either water and the sports drink and that the milk with added sodium would be the most effective drink due to the extra sodium it contained. We also hypothesised that the sports drink would be similar to or slightly better than water in its rehydration effectiveness.

\section{Methods}

Eleven healthy volunteers (five male, six female; age 24 (SD 4) years; height 1.66 (SD 0.07) m; mass $65.6(\mathrm{SD} 7.2) \mathrm{kg}$ ) agreed to participate in this investigation. At the time of the study all subjects were taking part in regular physical activity, but were not accustomed to exercise in a warm environment. Due to the nature of the investigation, those with known lactose intolerance were excluded. Prior to volunteering, all subjects received written details outlining the nature of the study. Following any questions regarding the protocol, a written statement of consent was signed. The protocol received approval from the University Ethical Advisory Committee.

Subjects were required to complete one familiarisation trial followed by four experimental trials. The familiarisation trial followed the same format as the experimental trials, with the exception of a shortened post-exercise recovery period, and was intended to ensure the participants were accustomed to the protocol prior to the start of the study. Each subject completed four experimental trials, randomised and administered in a crossover manner, separated by at least $7 \mathrm{~d}$. To help ensure metabolic conditions were similar before each trial, subjects were instructed to record dietary intake and physical activity during the $2 \mathrm{~d}$ before the first trial, and to replicate this in the $2 \mathrm{~d}$ prior to the subsequent experimental trials. No alcohol consumption was permitted in the $24 \mathrm{~h}$ before each trial and subjects were also instructed to avoid strenuous exercise during this time.

All experimental trials commenced in the morning following an overnight fast, other than the ingestion of approximately $500 \mathrm{ml}$ plain water consumed approximately $90 \mathrm{~min}$ before arrival in the laboratory for the start of the trial. Upon arrival in the laboratory, subjects were asked to empty their bladder into a collection container and complete a subjective feelings questionnaire. Subjects then entered a climatic chamber maintained at a temperature of $35.0 \pm 0.5^{\circ} \mathrm{C}$ and relative humidity of $56 \pm 7 \%$, and nude body mass was measured to the nearest $10 \mathrm{~g}$ (CFW150 digital scale; Adam, Milton Keynes, UK). The subjects then completed a series of $10 \mathrm{~min}$ periods of cycle exercise at a workload of $2 \mathrm{~W} / \mathrm{kg}$ body mass. A 5 min rest period separated successive blocks of exercise, during which the subject towelled dry and nude body mass was recorded to monitor body mass loss. Sweat losses were determined for each period of exercise through changes in body mass and this pattern of activity and rest continued until the subject had lost approximately $1.7 \%$ of their initial body mass. Subjects then left the warm environment and were asked to shower and towel dry, before being reweighed to determine the final body mass loss.

Drinking commenced exactly $20 \mathrm{~min}$ after the end of exercise and on each trial one of four experimental drinks was consumed. The drinks ingested during the experimental trials were milk $(0.2 \%$ fat; Tesco Ltd, Cheshunt, UK; trial M) and milk (0.2\% fat) with an additional $20 \mathrm{mmol} / \mathrm{l} \mathrm{NaCl}$ (trial $\mathrm{M}+\mathrm{Na}$ ), water (Aquapura, Basingstoke, $\mathrm{UK}$; trial $\mathrm{W}$ ) and a commercially available carbohydrate-electrolyte sports drink (Powerade, Coca Cola Ltd, London, UK trial $\mathrm{CE})$. The composition of the drinks ingested is shown in Table 1. The drink volume consumed was equal to $150 \%$ of the volume of the body mass lost during exercise and was provided in four equal boluses at $15 \mathrm{~min}$ intervals, giving a total drinking time of $60 \mathrm{~min}$. Subjects then rested in the laboratory for a further $4 \mathrm{~h}$, to allow recovery to be monitored. No food or drink was consumed during this recovery period. Subjects were asked to empty their bladder as completely as possible at the end of each hour during the recovery period. The urine volume was measured using a volumetric cylinder and a $5 \mathrm{ml}$ aliquot was retained for analysis. Any additional urine produced during the recovery period was collected and added to the bolus produced at the end of each hour.

The subjective response to the drink taste and associated feelings relating to thirst, hunger and tiredness were assessed using a series of $100 \mathrm{~mm}$ visual analogue scales. These were completed by the subjects on seven occasions over each trial: upon entering the laboratory, following the completion of exercise, immediately after the end of drinking and each hour during the recovery period.

The $5 \mathrm{ml}$ aliquot of each urine sample collected was stored at $4{ }^{\circ} \mathrm{C}$ for analysis of sodium and potassium concentrations by flame photometry (Corning 410C; Corning, New York, USA), chloride by coulometric titration (Jenway PCLM 3; Jenway, 
Table 1. Composition and energy content of experimental drinks*

(Mean values and standard deviations)

\begin{tabular}{|c|c|c|c|c|c|c|c|c|}
\hline & \multicolumn{2}{|c|}{ Water } & \multicolumn{2}{|c|}{$\mathrm{CE}$} & \multicolumn{2}{|c|}{ Milk } & \multicolumn{2}{|c|}{ Milk $+\mathrm{Na}$} \\
\hline & Mean & SD & Mean & SD & Mean & SD & Mean & SD \\
\hline Carbohydrate (g/l) & 0 & & $60 \dagger$ & & $50 \ddagger$ & & $50 \ddagger$ & \\
\hline Fat $(\mathrm{g} / \mathrm{l})$ & 0 & & 0 & & 3 & & 3 & \\
\hline Protein $(g / l)$ & 0 & & 0 & & 36 & & 36 & \\
\hline Energy density (kJ/l) & 0 & & 1020 & & 1480 & & 1480 & \\
\hline Sodium $(\mathrm{mmol} / \mathrm{l})$ & 0.3 & 0.5 & 23.0 & 0.7 & 38.6 & 1.7 & $58 \cdot 0$ & 1.5 \\
\hline Potassium (mmol/l) & 0.0 & 0.0 & $2 \cdot 0$ & 0.0 & $45 \cdot 2$ & $1 \cdot 7$ & $47 \cdot 0$ & 2.5 \\
\hline Chloride (mmol/l) & 0 & 0 & 1 & 0 & 35 & 1 & 55 & 2 \\
\hline Osmolality (mosmol/kg) & 0 & 0 & 283 & 2 & 299 & 3 & 345 & 4 \\
\hline
\end{tabular}

$\mathrm{CE}$, carbohydrate-electrolyte sports drink (Powerade); Milk $+\mathrm{Na}$, milk with added $\mathrm{NaCl}$.

* Macronutrient content and energy density were obtained from the manufacturers and the Dairy Council, UK. Drink electrolyte content and osmolality were measured in the laboratory.

† Glucose and maltodextrin.

†Lactose.

Dunmow, Essex, UK) and osmolality by freezing point depression (Gonotech 030; YSI, Farnborough, UK).

Data are presented as means and standard deviations unless otherwise stated. To identify differences in normally distributed results, two-way (time-by-trial) repeated measures ANOVA were employed. Where a significant interaction was apparent, pair-wise differences were evaluated using Tukey's post hoc procedure. For the purpose of hypothesis testing, the $95 \%$ level of confidence was predetermined as the minimum criterion to denote a statistical difference $(P<0 \cdot 05)$.

\section{Results}

Mean body mass loss during the dehydration protocol was 1.19 (SD 0.28$) \mathrm{kg}$, representing a loss of 1.8 (SD 0.2) \% of initial body mass. There was no difference in the body mass loss between the four experimental trials $(P=0.644)$ and consequently the volume of drink ingested was not different between trials and amounted to 1.79 (SD 0.42) litres.

\section{Urine output and fluid balance}

The volume of urine excreted each hour over the course of the experiment is presented in Fig. 1. The drink ingested following exercise significantly altered the volume of urine produced over the course of the $4 \mathrm{~h}$ recovery period $(P<0 \cdot 001)$. There was little change in hourly urine volume over the recovery period during both milk trials, whereas a marked increase was apparent between 1 and $2 \mathrm{~h}$ after drinking in the $\mathrm{W}$ and $\mathrm{CE}$ trials. This was reflected in the cumulative urine output observed over the course of the recovery period $(P<0.001$; Fig. 2), with significantly less volume excreted in trials $M$ (611 (SD 207) $\mathrm{ml}$ ) and $\mathrm{M}+\mathrm{Na}(550$ (SD 141) $\mathrm{ml}$ ) compared to $\mathrm{CE}$ (1184 (SD 321) $\mathrm{ml}$ ) and W (1205 (SD 142) ml). By $1 \mathrm{~h}$ after the end of drinking, subjects had retained significantly less of the water and sports drink than of the two milk drinks (Fig. 3; $P<0 \cdot 001$ ). By the end of the recovery period the fraction of drink retained was 36 (SD 10) \% in trial W, 38 (SD 16) \% in trial CE, 69 (SD 10) \% in trial M and $72(\mathrm{SD} 4) \%$ in the $\mathrm{M}+\mathrm{Na}$ trial $(P<0.001)$.
Mean changes in whole body net fluid balance are displayed in Fig. 3. The dehydration protocol induced a mean fluid loss of 1.19 (SD 0.29), 1.19 (SD 0.28), 1.19 (SD 0.31) and 1.21 (SD $0 \cdot 29)$ litres in the $\mathrm{W}, \mathrm{CE}, \mathrm{M}$ and $\mathrm{M}+\mathrm{Na}$ trials, respectively $(P=0.644)$. Ingestion of 1.79 (SD 0.42$)$ litres of fluid $(150 \%$ of body mass lost) resulted in a net positive fluid balance of 0.56 (SD 0.06) litres at the end of the $1 \mathrm{~h}$ drinking period in all trials. The ongoing urine excretion observed throughout the $\mathrm{W}$ and CE trials resulted in a return to euhydration $1 \mathrm{~h}$ after the end of drinking (W-0.02 (SD 0.15) and CE -0.05 (SD 0.23) litres), with further losses resulting in a net negative fluid balance of 0.61 (SD 0.11) litres in the $\mathrm{W}$ trial and 0.59 (SD 0.28) litres in the CE trial at the end of the recovery period $(P<0 \cdot 001)$. As the ingestion of both milk and milk with added $\mathrm{NaCl}$ resulted in significantly less diuresis and consequently a greater percentage of drink retention, subjects remained in net positive fluid balance $1 \mathrm{~h}$ after the end of the drinking period and then remained euhydrated until the end of

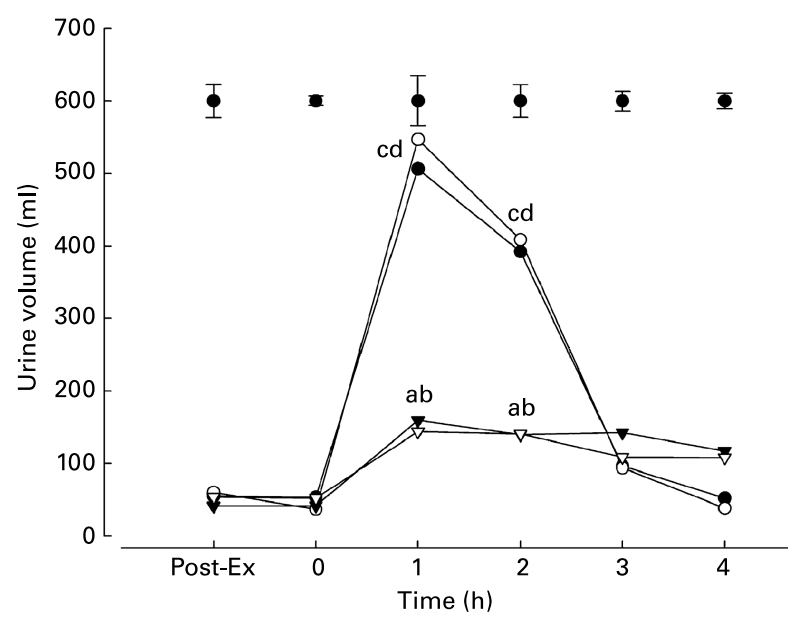

Fig. 1. Urine output over time for the four experimental trials $(\bullet$, trial $\mathbf{W}$, water; $\mathrm{O}$, trial $\mathrm{CE}$, carbohydrate-electrolyte sports drink; $\mathbf{\nabla}$, trial $\mathrm{M}$, milk; $\nabla$, trial $\mathrm{M}+\mathrm{Na}$, milk with added $\mathrm{NaCl}$ ). Values are means with group standard errors depicted by vertical bars. ${ }^{a, b, c, d}$ Mean values were significantly different from corresponding values in $W, C E, M$ and $M+N a$ trials, respectively $(P<0.05)$. Post-Ex, post-exercise. 


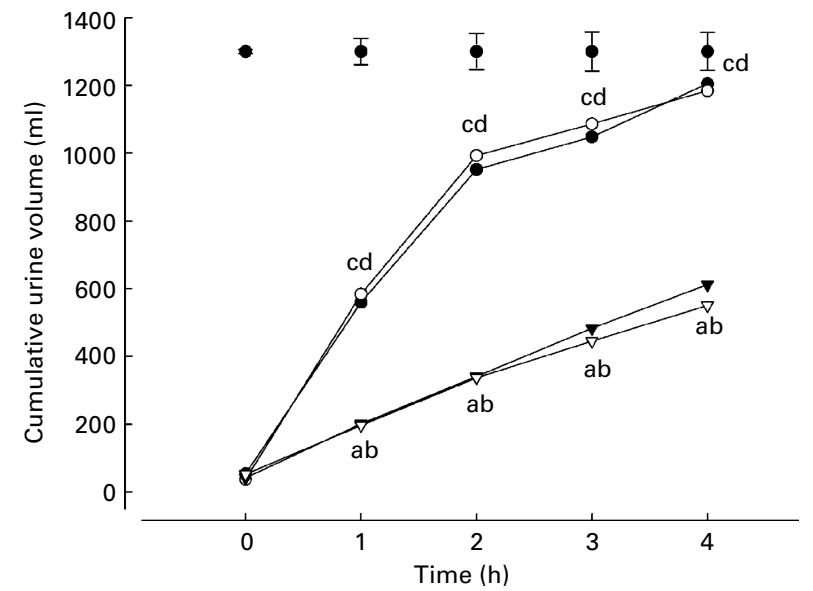

Fig. 2. Cumulative urine output over the course of the protocol $(\bullet$, trial $W$, water; $\mathrm{O}$, trial $\mathrm{CE}$, carbohydrate-electrolyte sports drink; $\mathbf{\nabla}$, trial $\mathrm{M}$, milk; $\nabla$, trial $\mathrm{M}+\mathrm{Na}$, milk with added $\mathrm{NaCl}$ ). Values are means with group standard errors depicted by vertical bars. ${ }^{a, b, c, d}$ Mean values were significantly different from corresponding values in $\mathrm{W}, \mathrm{CE}, \mathrm{M}$ and $\mathrm{M}+\mathrm{Na}$ trials, respectively $(P<0.05)$.

the $4 \mathrm{~h}$ recovery period when net fluid balance in trial $\mathrm{M}$ was $0.01(\mathrm{SD} 0.19)$ litres and in trial $\mathrm{M}+\mathrm{Na}$ was 0.06 (SD 0.08) litres.

\section{Urinary electrolyte excretion and urine osmolality}

There was a significant difference in the cumulative urinary electrolyte excretion after drinking during each trial $(\mathrm{Na}$, $P=0.027 ; \mathrm{K}, P=0.035 ; \mathrm{Cl}, P=0.006$; Table 2 ). The smallest urinary electrolyte loss was observed during the water trial and the greatest amount excreted was apparent in the $\mathrm{M}+\mathrm{Na}$ trial, with this difference reaching significance by the end of the recovery period $(P<0.05)$. Pre-trial urine osmolality was not different between trials $(P=0.672)$. At $1 \mathrm{~h}$ after the end of drinking there was a significant fall in urine osmolality observed following the ingestion of water

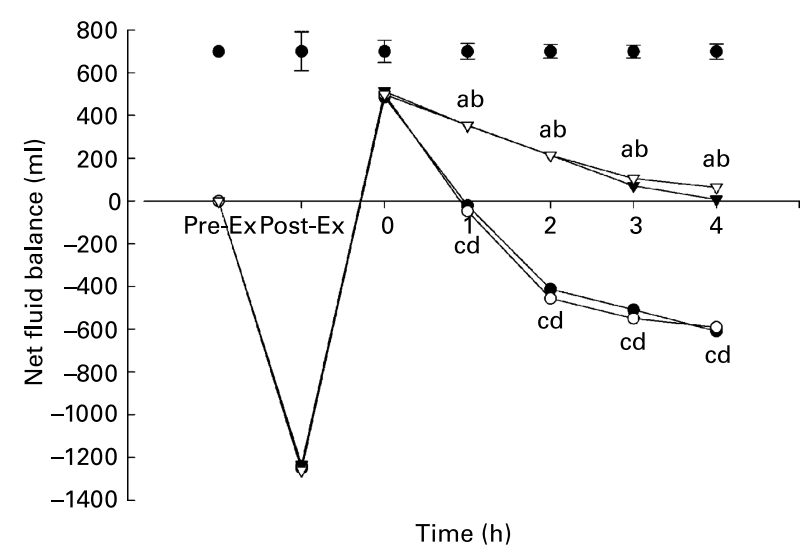

Fig. 3. Whole body net fluid balance over the course of the protocol ( $\bullet$, trial $\mathrm{W}$, water; $\mathrm{O}$, trial $\mathrm{CE}$, carbohydrate-electrolyte sports drink; $\mathbf{\nabla}$, trial M, milk; $\nabla$, trial $\mathrm{M}+\mathrm{Na}$, milk with added $\mathrm{NaCl}$ ). Values are means with group standard errors depicted by vertical bars. ${ }^{a, b, c, d}$ Mean values were significantly different from corresponding values in $\mathrm{W}, \mathrm{CE}, \mathrm{M}$ and $\mathrm{M}+\mathrm{Na}$ trials, respectively $(P<0.05)$. Post-Ex, post-exercise; Pre-Ex, pre-exercise.
$(P=0.030)$ and the sports drink $(P=0 \cdot 038)$, but this response was not apparent in the milk trials $(P=1 \cdot 000)$.

\section{Subjective feelings}

The subjects' responses to the drink taste and associated feelings relating to the drink at rest and during exercise are presented in Fig. 4(a-c). There was no difference between the trials in any of these measures on arrival in the laboratory. There was a marked increase in perceived thirst reported immediately following exercise. The ingestion of the experimental drinks reduced feelings of thirst, but this sensation gradually returned in all trials throughout the recovery period. Feelings of stomach fullness and bloatedness followed the opposite pattern. There was a difference in perceived feelings of hunger between trials $(P=0.020)$. In general subjects felt more hungry during the recovery period following the ingestion of water, whereas this sensation was delayed during the $\mathrm{CE}, \mathrm{M}$ and $\mathrm{M}+\mathrm{Na}$ trials.

There were no differences in reported feelings of mouth taste $(P=0.066)$, tiredness $(P=0.066)$, alertness $(P=0.403)$, concentration $(P=0.584)$, headache $(P=0.059)$, refreshment $(P=0.576)$ or energy $(P=0.787)$ between trials (Fig. $4(\mathrm{~b}))$.

There were clear differences between trials in the perceived taste and palatability of the drinks when assessed immediately following the drinking period. The subjects reported that the carbohydrate-electrolyte solution was sweeter $(P=0.001)$ and there was a tendency for it to be more palatable $(P=0.087)$ than the other experimental drinks. The subjects reported that the milk and milk with added $\mathrm{NaCl}$ were slightly more salty and bitter than the other drinks, but these feelings were not significantly different from those reported in the other trials (salt $P=0 \cdot 340$; bitter $P=0 \cdot 123$ ).

\section{Discussion}

In the present study, the effectiveness of low-fat milk at promoting the restoration of whole-body net fluid balance after exercise-induced dehydration was investigated. The results suggest that milk is more effective at replacing sweat losses and maintaining euhydration than plain water or a commercially available sports drink following exercise-induced dehydration by approximately $2 \%$ of initial body mass. However, there was no further benefit gained by adding an additional $20 \mathrm{mmol} / \mathrm{l} \mathrm{NaCl}$ to the milk. The ingestion of water and carbohydrate-electrolyte solution resulted in a marked diuresis during the $2 \mathrm{~h}$ following drinking, but this response was not apparent during the $\mathrm{M}$ and $\mathrm{M}+\mathrm{Na}$ trials. Consequently, at the end of the $4 \mathrm{~h}$ recovery period a $600 \mathrm{ml}$ difference in whole-body net fluid balance was apparent between the milk trials and the $\mathrm{W}$ and $\mathrm{CE}$ trials. It is likely that a difference of this magnitude would not be sufficient to influence exercise performed in temperate conditions, but mild levels of dehydration may significantly influence exercise capacity in a warm environment (Cheuvront et al. 2003; Coyle, 2004).

The main factors influencing the process of post-exercise rehydration are the volume and composition of the fluid ingested (Shirreffs et al. 2004). Given that obligatory urine losses persist, even when significantly hypohydrated, it is important to ensure that the drink volume ingested is greater than the volume of sweat lost during exercise. Previous 
Table 2. Cumulative urinary electrolyte excretion and urine osmolality following rehydration

(Mean values and standard deviations)

\begin{tabular}{|c|c|c|c|c|c|c|c|c|c|c|}
\hline & \multicolumn{2}{|c|}{$\mathrm{Oh}$} & \multicolumn{2}{|c|}{$1 \mathrm{~h}$} & \multicolumn{2}{|c|}{$2 \mathrm{~h}$} & \multicolumn{2}{|c|}{$3 \mathrm{~h}$} & \multicolumn{2}{|c|}{$4 \mathrm{~h}$} \\
\hline & Mean & SD & Mean & SD & Mean & SD & Mean & SD & Mean & SD \\
\hline \multicolumn{11}{|c|}{ Sodium (mmol) } \\
\hline Water & 4.9 & $2 \cdot 8$ & $12 \cdot 3$ & $5 \cdot 1$ & $18 \cdot 7$ & $6 \cdot 4$ & $24 \cdot 3$ & $7 \cdot 7$ & $31.9^{d}$ & 3.5 \\
\hline CE & $4 \cdot 3$ & $3 \cdot 0$ & $13 \cdot 1$ & $6 \cdot 3$ & $23 \cdot 6$ & 8.4 & $37 \cdot 8$ & $17 \cdot 4$ & $52 \cdot 8$ & $16 \cdot 3$ \\
\hline Milk & $5 \cdot 2$ & $2 \cdot 7$ & $16 \cdot 3$ & $6 \cdot 4$ & $31 \cdot 0$ & 14.5 & $42 \cdot 7$ & $21 \cdot 8$ & 54.9 & 21.4 \\
\hline Milk $+\mathrm{Na}$ & $7 \cdot 9$ & $5 \cdot 3$ & $25 \cdot 0$ & $10 \cdot 7$ & 43.5 & $18 \cdot 7$ & $58 \cdot 2$ & $24 \cdot 8$ & $82 \cdot 4^{a}$ & $22 \cdot 1$ \\
\hline \multicolumn{11}{|c|}{ Potassium (mmol) } \\
\hline Water & $4 \cdot 3$ & $2 \cdot 8$ & $11 \cdot 6$ & $5 \cdot 8$ & $17 \cdot 8^{\mathrm{d}}$ & $8 \cdot 1$ & $22 \cdot 3^{\mathrm{d}}$ & $9 \cdot 2$ & $25 \cdot 2^{d}$ & $10 \cdot 2$ \\
\hline CE & $4 \cdot 2$ & 2.5 & $10 \cdot 5$ & $5 \cdot 1$ & $18 \cdot 3$ & 9.4 & $22 \cdot 9$ & $11 \cdot 2$ & $26 \cdot 0$ & $10 \cdot 2$ \\
\hline Milk & $5 \cdot 7$ & $3 \cdot 2$ & $17 \cdot 5$ & 9.4 & $32 \cdot 3$ & $15 \cdot 3$ & $44 \cdot 0$ & $20 \cdot 1$ & $54 \cdot 0$ & $19 \cdot 1$ \\
\hline Milk $+\mathrm{Na}$ & $7 \cdot 3$ & $5 \cdot 0$ & $19 \cdot 7$ & $7 \cdot 7$ & $36 \cdot 6^{a}$ & $11 \cdot 8$ & $49 \cdot 6^{a}$ & $15 \cdot 8$ & $64 \cdot 0^{\mathrm{a}}$ & $18 \cdot 2$ \\
\hline \multicolumn{11}{|c|}{ Chloride (mmol) } \\
\hline Water & $3 \cdot 8$ & $2 \cdot 8$ & $10 \cdot 4$ & $5 \cdot 3$ & $15 \cdot 8^{d}$ & $6 \cdot 6$ & $20 \cdot 2$ & $7 \cdot 9$ & $26 \cdot 6^{d}$ & $6 \cdot 2$ \\
\hline CE & $3 \cdot 8$ & 3.5 & $10 \cdot 2$ & $6 \cdot 6$ & $17 \cdot 9$ & $9 \cdot 6$ & 23.5 & $11 \cdot 1$ & $35 \cdot 4$ & 9.5 \\
\hline Milk & $3 \cdot 6$ & $2 \cdot 3$ & $13 \cdot 3$ & $5 \cdot 0$ & $25 \cdot 9$ & 9.4 & $35 \cdot 7$ & $14 \cdot 0$ & $48 \cdot 2$ & $16 \cdot 5$ \\
\hline Milk $+\mathrm{Na}$ & $5 \cdot 7$ & $3 \cdot 7$ & 23.2 & $9 \cdot 0$ & $42 \cdot 7^{\mathrm{a}}$ & $15 \cdot 3$ & $55 \cdot 2$ & 21.4 & $73 \cdot 3^{\mathrm{a}}$ & $23 \cdot 7$ \\
\hline \multicolumn{11}{|c|}{ Osmolality (mosmol/kg) } \\
\hline Water & 718 & 155 & $99^{\mathrm{cd}}$ & 49 & $149^{\text {cd }}$ & 75 & 424 & 129 & 483 & 99 \\
\hline $\mathrm{CE}$ & 706 & 149 & $92^{\mathrm{cd}}$ & 49 & $129^{\text {cd }}$ & 64 & 395 & 151 & 701 & 77 \\
\hline Milk & 714 & 253 & $509^{\mathrm{ab}}$ & 250 & $607^{\mathrm{ab}}$ & 223 & 515 & 211 & 494 & 315 \\
\hline Milk $+\mathrm{Na}$ & 832 & 179 & $636^{a b}$ & 296 & $686^{\mathrm{ab}}$ & 179 & 646 & 205 & 599 & 201 \\
\hline
\end{tabular}

$\mathrm{CE}$, carbohydrate-electrolyte sports drink (Powerade); milk $+\mathrm{Na}$, milk with added $\mathrm{NaCl}$.

a,b,c,d Mean values were significantly different from corresponding values in water, CE, milk and milk + Na trials, respectively $(P<0 \cdot 05)$.

work has demonstrated that a volume greater than the estimated sweat volume lost must be replaced for effective restoration of fluid balance to be achieved (Shirreffs et al. 1996). Data from the present study trials $\mathrm{W}$ and CE, along with evidence from previous investigations (Shirreffs et al. 1996), highlight that simply drinking a volume in excess of sweat losses is not in itself sufficient to restore whole-body net fluid balance. The ingestion of a large volume of dilute fluid results in haemodilution, characterised by a fall in serum electrolyte concentrations and osmolality, resulting in the stimulation of diuresis (Nose et al. 1988).

The addition of electrolytes, in particular sodium, to a postexercise rehydration drink has been demonstrated to enhance the rehydration process (Maughan et al. 1994). There appears to be a direct relationship between the amount of sodium in a rehydration solution and the fraction of drink retained following ingestion (Maughan \& Leiper, 1995; Shirreffs \& Maughan, 1998). The milk used in the present study contained a moderate quantity of sodium (approximately $35 \mathrm{mmol} / \mathrm{l}$ ) in comparison to many foods, but it contains more than most commercially available sports drinks and other drinks (Shirreffs, 2003). It is worth noting that the measured sodium content of the milk consumed in the present study was higher than reported by some (Burke, 1996), but not all sources (Karp et al. 2006). It is likely that the presence of sodium along with a relatively large quantity of potassium (approximately $45 \mathrm{mmol} / \mathrm{l}$ ) in milk accounts for the effectiveness of milk at restoring fluid balance following exercise-induced dehydration. The role of potassium in the post-exercise rehydration process is less established, but as the major intracellular cation it has the potential to aid restoration of fluid balance through the retention of water in the intracellular space (Maughan et al.
1994; Shirreffs et al. 2004). It is now accepted that for the rehydration process to be optimised it is important to replace not only the fluid, but also the electrolytes lost in sweat (Shirreffs \& Maughan, 1998).

The large difference in urinary electrolyte excretion between trials was related to the differences in the quantities of electrolytes consumed via the drinks. As the addition of $20 \mathrm{mmol} / \mathrm{l} \mathrm{NaCl}$ to the milk had no additional effect on net fluid balance $(P=1.000)$ over that of commercially available milk, and coupled with the slightly elevated urinary electrolyte excretion, it seems possible that the additional $\mathrm{NaCl}$ was simply expelled by the kidneys. It seems that a difference between drinks in their sodium concentration of around $20 \mathrm{mmol} / \mathrm{l}$ is at the borderline of inducing a significant effect on whole-body hydration status. Increasing the milk sodium concentration from 38 to $58 \mathrm{mmol} / \mathrm{l}$ resulted in no different effect on whole-body fluid balance status. A similar difference in sodium concentration exists between the water and sports drink in the present study and again no measurable difference in hydration status was apparent between these two trials. The result is consistent with others in the published literature where differences in sodium concentration of drinks has been investigated (Shirreffs \& Maughan, 1998).

While the electrolyte content of the test drinks may be largely responsible for the differences seen, it is likely that the milk emptied from the stomach at a slower rate than the water and sports drink. This, in turn, may have implications for subsequent fluid balance. Milk has a higher energy density than both water and the sports drink (see Table 1), largely due to the presence of protein and fat in addition to the carbohydrate. Energy density has been shown to be one of the most important variables that regulate the rate at which 
(a)
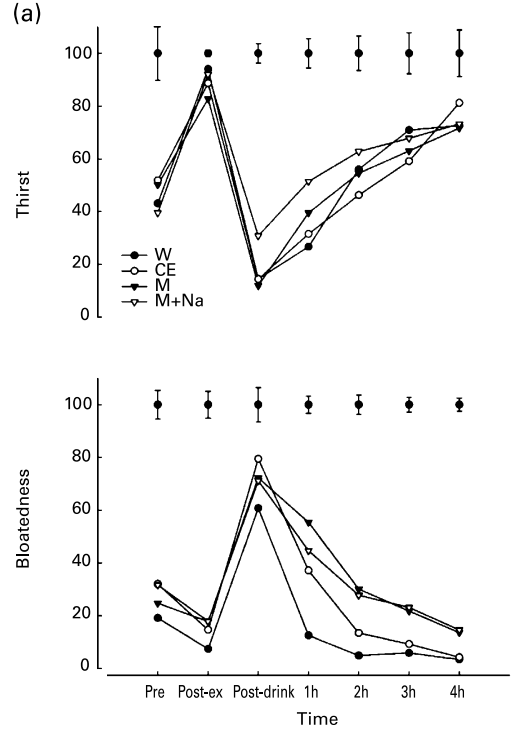

(b)
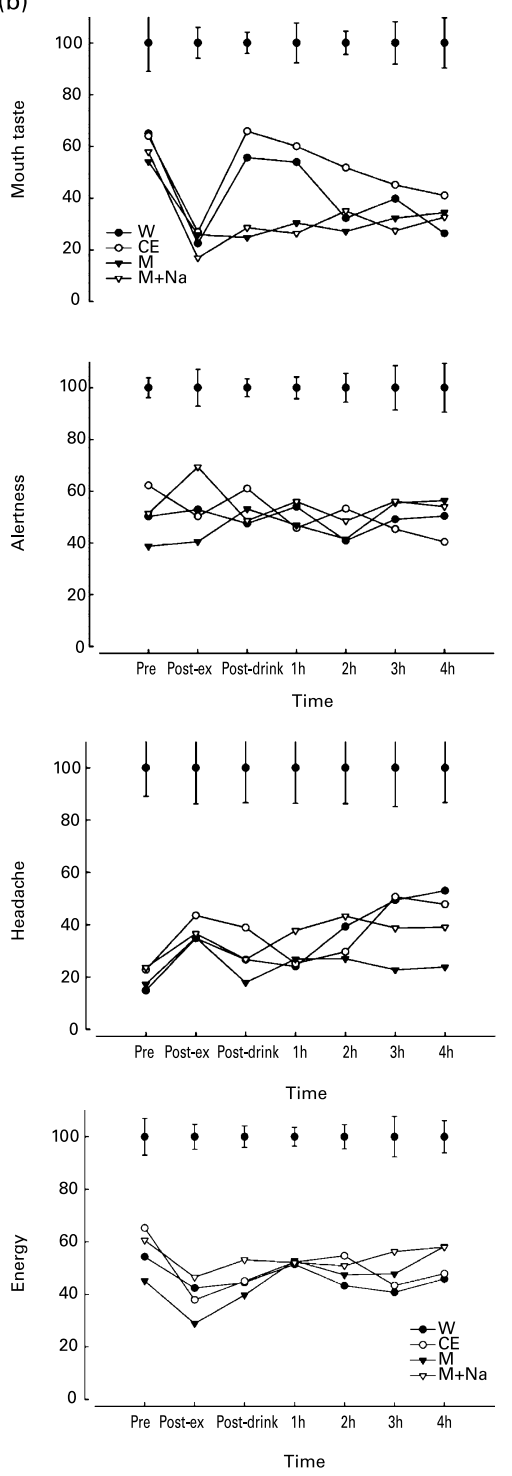
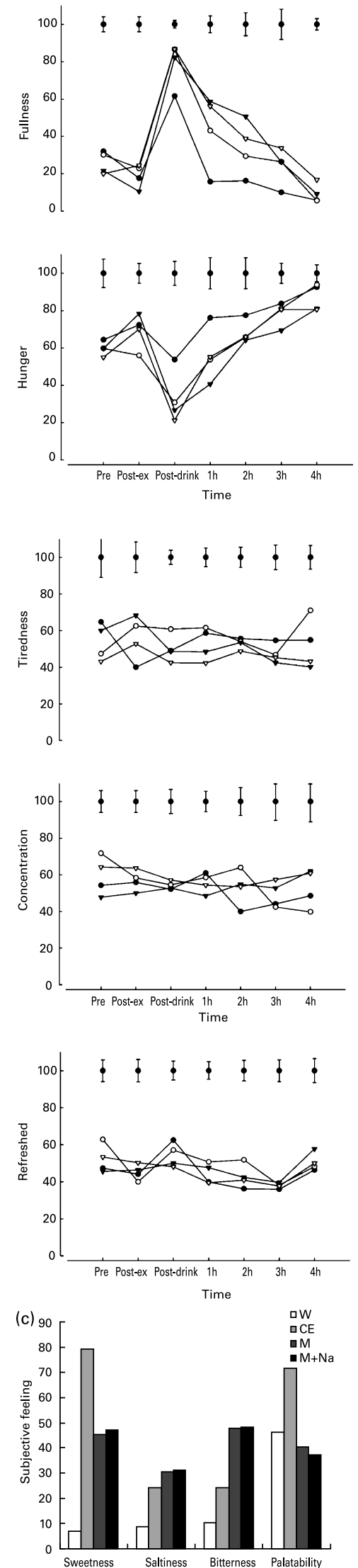

Fig. 4. Subjective feelings of thirst, fullness, bloatedness and hunger (a) and mouth taste, tiredness, alertness, concentration, headache, refreshment and energy (b) reported during the course of the protocol. Values are means with group standard errors depicted by vertical bars. Where present, statistical differences are described in the text. Post-Ex, post-exercise; Pre, pre-exercise. (c), Perceived taste characteristics and palatability of the experimental drinks ( $\square$, trial W, water; $\square$, trial CE, carbohydrate-electrolyte sports drink; $\square$, trial $\mathrm{M}$, milk; $\mathbf{\square}$, trial $\mathrm{M}+\mathrm{Na}$, milk with added $\mathrm{NaCl}$ ). Where present, statistical differences are described in the text. 
ingested solutions empty from the stomach: the nature of the energy-containing nutrients has a minor role (Vist \& Maughan, 1995; Calbet \& MacLean, 1997; Maughan et al. 2004a). Using the data of Calbet \& Maclean (1997), we can estimate that the half emptying time of our milk solutions would be in the order of $14 \%$ slower than that of the sports drink. Any delay in gastric emptying is likely to reduce the rate of influx of fluid into the circulation and limit the changes in the volume and osmolality of the vascular space that lead to stimulation of urine production. This is partially supported by data collected from subjective feelings questionnaires completed by the subjects. The questionnaires suggest a greater sensation of stomach fullness after ingesting milk than at the same time-points during the CE trial. However, as fluid balance was monitored for $4 \mathrm{~h}$ after the end of the $1 \mathrm{~h}$ drinking period, we are confident that sufficient time was allowed for all of the drinks to have emptied from the stomach of the subjects and to have been absorbed in the intestine. The subjective feeling data indicate that the low-fat milk was well tolerated in most individuals following prolonged exercise in a warm environment, compared to the other drinks studied. Some individuals did complain of feelings of excessive bloatedness due to the large volume of fluid ingested, but the subjective feeling data do not suggest that this sensation was any more pronounced than during the other trials.

When considering the practical application of these findings it is important to consider the potential for problems due to lactose intolerance in susceptible individuals. Estimates suggest that between 5 and $15 \%$ of the UK population possess some form of lactose intolerance (de Vrese et al. 2001). This figure appears to be the norm for most western countries, and the authors are unaware of any reported differences between sedentary and athletic populations. Due to the substantial levels of dehydration that often accompany exercise in the heat, effective post-exercise rehydration may require the ingestion of large volumes of fluid, in a relatively short period of time. This may result in gastrointestinal disturbance for individuals who are affected by mild lactose intolerance that does not present itself when consuming more moderate amounts of milk. Additionally, problems may arise with the application of these data by some Asian populations, who experience much greater incidences of lactose intolerance (90-100\%; de Vrese et al. 2001).

In conclusion, the results of the present study suggest that milk is an effective solution to promote recovery following mild exercise-induced dehydration, compared to the ingestion of the same volume of either plain water or a commercially available sports drink, and can be considered for use after exercise by everyone except those individuals who have lactose intolerance. The naturally high electrolyte content of milk ( $\mathrm{Na} 38 \mathrm{mmol} / \mathrm{l} ; \mathrm{K} 45 \mathrm{mmol} / \mathrm{l} ; \mathrm{Cl} 35 \mathrm{mmol} / \mathrm{l}$ ) aided in the retention of fluid and the maintenance of euhydration $4 \mathrm{~h}$ after the end of drinking, although differences in gastric emptying rates due to the presence of protein and fat in the milk cannot be discounted. It is possible to speculate, based on previously published work, that the ingestion of water and the sports drink resulted in a marked haemodilution, stimulating the formation of urine and the rapid return to a net negative fluid balance. Given that hypohydration results in an increase in cardiovascular and thermoregulatory strain, and a reduction in exercise capacity in the heat, it is important to ensure that fluid losses accrued during exercise are replaced prior to the performance of a subsequent exercise bout.

\section{Acknowledgements}

This work was supported by a grant from the Milk Development Council.

\section{References}

Broad EM, Burke LM, Cox GR, Heeley P \& Riley M (1996) Body weight changes and voluntary fluid intakes during training and competition sessions in team sports. In J Sports Nutr Exerc Metab 6, 307-320.

Burke LM (1996) Rehydration strategies before and after exercise. Aust J Nutr Diet 53, S22-S26.

Burke LM \& Hawley JA (1997) Fluid balance in team sports. Guidelines for optimal practices. Sports Med 24, 38-54.

Calbet JAL \& MacLean (1997) Role of calorie content on gastric emptying in humans. J Physiol 498, 553-559.

Cheuvront S, Carter R \& Sawka MN (2003) Fluid balance and endurance exercise performance. Curr Sports Med Rep 2, 202-208.

Coyle EF (2004) Fluid and fuel intake during exercise. J Sports Sci 22, 39-55.

de Vrese M, Stegelmann A, Richter B, Fenselau S, Laue C \& Schrezenmeir J (2001) Probiotics - compensation for lactase insufficiency. Am J Clin Nutr 73, 421S-429S.

Gonzalez-Alonso J, Heaps CL \& Coyle EF (1992) Rehydration after exercise with common beverages and water. Int J Sport Med 13, 399-406.

Karp JR, Johnson JD, Tecklenburg S, Mickleborough TD, Fly AD \& Stager JM (2006) Chocolate milk as a post-exercise recovery aid. Int J Sports Nutr Exerc Metab 16, 78-91.

Maughan RJ \& Leiper JB (1995) Sodium intake and post-exercise rehydration in man. Eur J Appl Physiol Occup Physiol 71, 311-319.

Maughan RJ, Leiper JB \& Shirreffs SM (1996) Restoration of fluid balance after exercise-induced dehydration: effects of food and fluid intake. Eur J Appl Physiol 73, 317-325.

Maughan RJ, Leiper JB \& Vist GE (2004a) Gastric emptying and fluid availability after ingestion of glucose and soy protein hydrolysate solutions in man. Exp Phys 89, 101-108.

Maughan RJ, Merson SJ, Broad NP \& Shirreffs SM (2004b) Fluid and electrolyte intake and loss in elite soccer players during training. Int J Sports Nutr Exerc Metab 14, 333-346.

Maughan RJ, Owen JH, Shirreffs SM \& Leiper JB (1994) Post-exercise rehydration in man: effects of electrolyte addition to ingested fluids. Eur J Appl Physiol Occup Physiol 69, 209-215.

Maughan RJ, Shirreffs SM, Merson SJ \& Horswill CA (2005) Fluid and electrolyte balance in elite male football (soccer) players training in a cool environment. J Sports Sci 23, 73-79.

Nielsen B, Sjøgaard G, Ugelvig J, Knudsen B \& Dohlman B (1986) Fluid balance in exercise dehydration and rehydration with different glucose-electrolyte drinks. Eur J Appl Physiol 55, $318-325$.

Nose H, Mack GW, Shi XR \& Nadel ER (1988) Role of osmolality and plasma volume during rehydration in humans. J Appl Physiol 65, 325-331.

Ray ML, Bryan MW, Ruden TM, Baier SM, Sharp RL \& King DS (1998) Effect of sodium in a rehydration beverage when consumed as a fluid or meal. J Appl Physiol 85, 1329-1336.

Saat M, Singh R, Sirisinghe RG \& Nawawi M (2002) Rehydration after exercise with fresh young coconut water, 
carbohydrate-electrolyte beverage and plain water. $J$ Physiol Anthropol 21, 93-104.

Shirreffs SM (2003) The optimal sports drink. Sportmed Sporttraumatol 51, 25-29.

Shirreffs SM, Aragon-Vargas LF, Chamorro M, Maughan RJ, Serratosa L \& Zachwieja JJ (2005) The sweating response of elite professional soccer players to training in the heat. Int $J$ Sports Med 26, 90-95.

Shirreffs SM, Armstrong LE \& Cheuvront SN (2004) Fluid and electrolyte needs for preparation and recovery from training and competition. J Sports Sci 22, 57-63.
Shirreffs SM \& Maughan RJ (1998) Volume repletion after exerciseinduced volume depletion in humans: replacement of water and sodium losses. Am J Physiol 274, F868-F875.

Shirreffs SM, Taylor AJ, Leiper JB \& Maughan RJ (1996) Post-exercise rehydration in man: effects of volume consumed and drink sodium content. Med Sci Sports Exerc 28, 1260-1271.

Vist GE \& Maughan RJ (1995) The effect of osmolality and carbohydrate content on the rate of gastric emptying of liquids in man. J Physiol 486, 523-531.

Yawata T (1990) Effect of potassium solution on rehydration in rats: comparison with sodium solution and water. Jap J Physiol 40, 369-381. 